\title{
Factors Affecting the Career Choice of First-Year Student Teachers*
}

\author{
J.G. Maree ${ }^{1}$ and N. Hislop-Esterhuizen
}

Department of Curriculum Studies, University of Pretoria, 0001, Pretoria

\section{A. Swanepoel and M.J. van der Linde}

Department of Statistics, University of Pretoria, 0001 Pretoria

\begin{abstract}
The lack of appropriately qualified teachers in South Africa is growing rapidly and frequency of debates about the decline in teacher numbers in South Africa is increasing. In this study, the results of an investigation into possible factors that impact on the career choice of student teachers are reported. The reasons why first-year student teachers at the University of Pretoria chose teaching as a career were studied by using a non-experimental design (survey design; administering a non-standardised questionnaire). The results revealed inter alia that a number of factors influence the career choice of first-year student teachers. Trends that emerged from the current study include the following: many more women than men enter the teaching profession; relatively few students who speak an African language choose education as a field of study and the role of parents in helping their children to choose a career cannot be underestimated.
\end{abstract}

*This article is an adapted version of an article that appeared recently in a local, Afrikaans-only journal (Suid-Afrikaanse Tydskrif vir Natuurwetenskap en Tegnologie) with an extremely limited, exclusively Afrikaans readership, which is totally different from the readership of the International Journal for Adolescence and Youth (IJAY). The editorial staff of the journal granted the authors permission to publish the article in IJAY or any other journal with a different, English readership.

${ }^{1}$ Correspondence should be addressed to Professor Kobus Maree, Faculty of Education, University of Pretoria, Groenkloof Campus, Groenkloof, Pretoria 0001, South Africa. Kobus.maree@up.ac.za. The authors would hereby like to express their appreciation to all the students who participated in this study. 
40

\section{INTRODUCTION}

Experts are increasingly expressing their concerns about the escalating imbalance between teacher demand and supply (Jansen, 2006). In fact, since the beginning of 2000 the media have regularly been speculating about the decline in teacher numbers in South Africa (SA) (Hislop-Esterhuizen, 2006). Crouch (2001) as well as Pretorius and Heard (2002:1) explain for example that institutions for higher education produce in the region of 5000 teachers per year, while more than 33000 new teachers are necessary to provide for the demand for teachers. The Department of Education confirms this problem in the National Plan for Higher Education (2001) and states that

\footnotetext{
"the chronic mismatch between the output of higher education and the needs of a modernising economy emphasises the shortages of the highly trained graduates"
}

The Human Sciences Research Council (HSRC) (2005) echoes this and confirms a decrease in the average number of registered teachers in South Africa. This trend has been perceived over the past seven years and a decline in the number of teachers, namely from 386735 to 368548 over the period 2003 to 2004, was reported (HSRC, 2005).

\section{THEORETICAL FOUNDATION}

\section{Review of possible causes for the imbalance between teacher demand and supply}

\section{The HIV and AIDS pandemic}

Quinn (2005) alleges that the mortality figure for adult women between the ages 20 and 49 showed the highest increase over the past decade. He also expresses concern about the future of South Africa's employees who are threatened by the HIV and AIDS pandemic in particular (Quinn, 2005).

\section{Teaching is considered a less attractive occupation}

Crouch and Perry (2003) are of the opinion that teaching is an attractive occupation for the younger person with a lower qualification. When a person gets older and more qualified, teaching seems to become less attractive as an occupation. 
Changes in the South African education system

The changes in the education system have led to uncertainty among many teachers. For example, Chisholm (2004: p.11) believes that Outcomes-based Education (OBE) may in some cases be seen as:

"excessively complex and that outcomes-based education could only work in well-resourced schools with highly qualified teachers and that poorly-qualified teachers in rural schools would be at sea when faced with the demands to create their own curricula and resources".

The so-called brain drain or outflow of qualified persons to other parts of the world

In the News Bulletin, mouthpiece of the Royal Society of South Africa (2003), reference is made to in excess of 65000 young South Africans who have left the country to work in the United Kingdom over the past five years. Although this figure does not refer exclusively to teachers who left the country, it does signify the current trend. Parker (2004) claims that the percentage of professionals who left the country in 2004 increased by $62 \%$, compared to a similar exodus reported in 2003.

Retirement of teachers from the profession

According to the Human Sciences Research Council (HSRC) (2005), approximately $55 \%$ of the 21358 teachers who participated in a South African research project on teachers indicated that they were considering leaving the profession. Reasons for this decision included inter alia the following:

- Inadequate salaries

- An increased workload

- Inadequate professional development

- Lack of professional recognition

- Dissatisfaction with the employment policy

- Not enough career satisfaction

- Dissatisfaction with salaries, working hours and workload.

Ngidi and Sibaya (2002) furthermore refer to the discouraging circumstances in which black teachers have to work in some schools. These teachers are expected to function in poor conditions such as crowded classrooms and to make do with inadequate equipment and insufficient facilities. 
Negative perceptions of teaching as a profession

Teaching as a profession is often the subject of negative media coverage. According to Butcher and Lewis (2003) the following negative teaching trends are often discussed in the media:

- The changing nature and composition of teaching as a profession.

- Changes in the roles required by the profession, for which teachers get no recognition from the community, parents or employers.

- Salaries that do not keep pace with the degree of difficulty and intensity of the profession.

- Limited opportunities for advancement afforded by teaching as a career.

Our experience with students entering into higher education institutions shows that they are usually aware of views such as those expressed by Butcher and Lewis (2003). Factors such as unemployment and concern about obtaining a position after having acquired a qualification also do not contribute to enhancing the image of the profession. When confronted with this spectrum of negative publicity, prospective entrants to the teaching profession often decide not to embrace teaching as a career.

\section{South African professional development viewed from an ecosystemic perspective}

The ecosystemic approach has been used as the point of departure in this study to emphasise the effect of subsystems on other systems. Thus, the individual's career choice is not perceived as the primary focus, but as part of a subsystem in interaction with other subsystems such as the home, parents and other persons who influence the learner's career choice.

\section{Ecosystemic Approach}

The culture, background and social environment in which a person functions cannot be ignored when professional development is considered. Cook, Heppner and O'Brien (2002) declare that their ecological career model offers a description of the way in which the values of the environment (macro systems) are in constant 
interaction with the milieu in which an individual is functioning (home, school and work). They also believe that this interaction influences possible career choices in a very real way (Cook, Heppner and O'Brien, 2002).

Arthur and McMahon (2005) regard the individual as a 'system' that cannot exist in isolation but has to form part of a larger contextual system. The broader subsystems influence the system (individual) and cognisance should be taken of this influence when focusing on career choice trends.

Fouad and Byars-Winston (2005) argue that, when intraindividual factors such as interest or decision making are focused on exclusively, other factors that could affect a person's career decision making may be lost sight of. Factors located outside these intra-individual factors include inter alia environmental factors that should also be taken into account. In a similar vein, Betz (1989) refers to the external environmental factors (such as family, peer group and social support system) that influence the pursuit of career objectives.

Internal (micro systems) and external (meso and macro systems) factors affect the career choices that individuals make. Osipow (in Arthur and McMahon, 2005) considers the factors influencing a person's behaviour to be as follows:

\footnotetext{
"Elements of social, personal, and economic situation within which individuals operate may be more explicitly analyzed, and the relationship of the larger systems to one another may be more clearly understood than in the traditional approaches to behavior, which tend to emphasize one major segment of the individual or the environment (p. 208)".
}

Further to the view of Osipow (1983), Splete and Freeman-George (in Hislop-Esterhuizen, 2006) add the following factors that may also influence career choice:

- Geographic location

- Heredity

- Family history

- Socioeconomic status

- Family composition

- Parenting style

- Parents' attitude towards own career

- Opportunities for education and work

- Available financial resources. 
(Note however that European views should not be applied directly to the situation in South Africa and that career choice trends should be understood within the South African context.)

\section{South African perspectives with regard to career choice trends in the local teaching context}

Against the background of an escalating shortage of teachers, we intend to investigate a number of factors that may affect the career choice of student teachers. Our point of departure is that a career choice can never be made in isolation, as is proposed inter alia by the ecosystemic approach. While micro and macro factors influence the individual's decision making, factors such as personality, environment and culture, as well as role models and significant others contribute to the individual's career choice. These factors, in turn, affect career opportunities and career exploration. Both career maturity and the career decisionmaking process may conceivably be influenced by the factors mentioned above, which may again influence the making of a career choice.

We approached our study from an ecosystemic angle in the sense that we believe that aspects such as culture, background and the social environment in which people are functioning cannot be ignored when professional development is considered. In fact, in our opinion the importance of the ecosystemic approach with regard to career choice trends cannot be overemphasised (Cook, Heppner and O'Brien, 2002). Quimby and O'Brien (2004:326) are of the opinion that the multifaceted nature of professional development has demanded that contextual factors be taken into account, especially when career decision making is at issue. As mentioned earlier, Arthur and McMahon (2005) regard the individual as a 'system' that cannot exist in isolation but that forms part of a larger contextual system. The broader subsystems affect the system (individual) and this effect should not be disregarded when focusing on career choice trends.

Fouad and Byars-Winston (2005) emphasise the fact that researchers should focus not only on intra-individual factors (e.g. interest), but also on factors outside these intra-individual factors (e.g. environmental factors). In this regard Betz (1989) refers to factors such as the family, peer group, as well as social support groups that influence the pursuit of career aims. The reader is reminded of Splete and Freeman-George's (1985) argument that factors such as the following may also influence career choice: 
geographic location; family history; socioeconomic status; family composition parenting style; parents' attitude towards their own career; opportunities for education and work; as well as available financial resources.

The preceding literature survey has given an indication of the way in which the questionnaire has been developed based on the literature on possible factors that may affect the career choice of first-year student teachers.

\section{RESEARCH DESIGN}

A non-experimental design (survey design; administering a non-standardised questionnaire) was used in this study. The experiences, perceptions, views and feelings of first-year teacher students were studied.

\section{Sampling}

For the purpose of this study it was decided to define the population as all novice first-year teacher students who registered at the Faculty of Education at the University of Pretoria (UP) for the first time during 2004. The students attended orientation lectures over a number of days. It was decided to consider all those students who were in orientation on a particular day as a cluster, and to select a specific day randomly. All the students in orientation on that particular day would comprise the sample. Such a sampling procedure is known as cluster sampling. This means that the respondents are selected on the grounds of requirements that they must be student teachers; they should have enrolled at UP for the first time in 2004; they should be heterogeneous in respect of origin, background, characteristics and features, and they should comprise all the students who enrolled on the selected day.

Summarising tables of the descriptive statistics are reported separately, followed by discussions of the results. In this section, the following aspects are focused on:

- The frequency distribution of the total group with regard to biographical information is provided and discussed briefly.

- The frequency distribution of the total group with regard to the major reasons for choosing teaching as a career, as well as their views of teaching as a profession are reflected according to themes. 
46

Primary and secondary biographical data

The following biographical information of the respondents was gathered:

- Gender.

- Age.

- Home language.

- Financial situation.

- Geographic location of place where respondent matriculated.

- Merit score (M score) obtained (end of Grade 12).

Four hundred and forty-two $(n=442)$ respondents participated in the study. During the implementation of the questionnaire, the respondents were registered as first-year teacher students at the Faculty of Education of the University of Pretoria. The respondents were able to understand, read and write Afrikaans and/or English. Table 1 indicates the gender of the respondents, while the age of the respondents is set out in Table 2. Respondents from different language groups were presented in the sample.

One hundred and one (23\%) male students and 340 (77\%) female students participated in the study. These figures are particularly informative, given the fact that the ratio men: women who are currently enrolled at UP is 47:53 (Vermeulen, 2008). These findings with regard to the distribution of male and female students are in line with the study by Cosser and Du Toit (2002), who found that more females $(66 \%)$ than males (34\%) enter teaching as a profession. Cosser and Du Toit (2002) furthermore found that men give a much lower rating to teaching as an occupation than to other occupations.

Next, the frequency distribution of the ages of respondents who participated in the study is set out in Table 2.

\section{TABLE 1}

Frequency distribution of the gender of respondents $(n=442)$

\begin{tabular}{lcccc}
\hline Gender & Frequency & Percentage & $\begin{array}{c}\text { Cumulative } \\
\text { frequency }\end{array}$ & $\begin{array}{c}\text { Cumulative } \\
\text { percentag }\end{array}$ \\
\hline Male & 101 & 22.85 & 101 & 22.85 \\
Female & 340 & 76.92 & 441 & 99.77 \\
Not indicated & 1 & 0.23 & 442 & 100.00 \\
\hline
\end{tabular}


TABLE 2

Age distribution of respondents $(n=442)$

\begin{tabular}{lrccc}
\hline Age & Frequency & Percentage & $\begin{array}{c}\text { Cumulative } \\
\text { frequency }\end{array}$ & $\begin{array}{c}\text { Cumulative } \\
\text { percentage }\end{array}$ \\
\hline <20 years old & 363 & 82.13 & 363 & 82.13 \\
> 20 years old & 74 & 16.74 & 437 & 98.87 \\
Not indicated & 5 & 1.13 & 442 & 100.00 \\
\hline
\end{tabular}

The frequency distribution of the ages of the respondents may be set out as follows: $363(82.13 \%)$ of the 442 respondents are 20 years and younger. Seventy-four respondents $(16.74 \%)$ are above the age of 20 years.

A total of $310(70.14 \%)$ of the 442 respondents who participated in the study were Afrikaans speaking; 85 (19.23\%) were English speaking and $38(8.59 \%)$ had an African language as their mother tongue. These figures highlight a particularly poor representation of students speaking an African language as home language in the sample researched. These results again correlate positively with the findings of a study performed by Cosser and Du Toit (2002), which points to the very small percentage of students

TABLE 3

Frequency distribution of the home language of respondents $(\mathrm{n}=442)$

\begin{tabular}{lcccc}
\hline & Frequency & Percentage & $\begin{array}{c}\text { Cumulative } \\
\text { frequency }\end{array}$ & $\begin{array}{c}\text { Cumulative } \\
\text { percentage }\end{array}$ \\
\hline English & 85 & 19.23 & 85 & 19.23 \\
Afrikaans & 310 & 70.14 & 395 & 89.37 \\
$\begin{array}{l}\text { African } \\
\text { languages }\end{array}$ & 38 & 8.59 & 433 & 97.96 \\
Other $^{2}$ & 9 & 2.04 & 442 & 100.00 \\
\hline
\end{tabular}

${ }^{2}$ African languages constitute a comprehensive term for inter alia: Ndebele, Northern Sotho, Southern Sotho, Swati, Tsonga, Tswana, Venda, Xhosa and Zulu. 


\section{TABLE 4}

Frequency distribution: Geographic location of school where respondent matriculated $(n=442)$

\begin{tabular}{lcccc}
\hline $\begin{array}{l}\text { Geographic } \\
\text { location }\end{array}$ & Frequency & Percentage & $\begin{array}{c}\text { Cumulative } \\
\text { frequency }\end{array}$ & $\begin{array}{c}\text { Cumulative } \\
\text { percentage }\end{array}$ \\
\hline Urban & 330 & 74.66 & 330 & 74.66 \\
Rural & 111 & 25.11 & 441 & 99.77 \\
Not indicated & 1 & 0.23 & 442 & 100.00 \\
\hline
\end{tabular}

with an African language as mother tongue who are studying at universities (inter alia in teaching-related fields).

Table 4 indicates the frequency distribution of the geographic location of the school where the respondent matriculated. By the way, the question as to whether the findings in this paper are potentially valid for all universities or only for traditionally Afrikaans-medium universities is by no means as simple to answer as it may appear. Despite an immediate reaction to say "only for traditionally Afrikaans-medium universities", the truth is that the University of Pretoria has over the past few years experienced a drastic change in the composition of its student teachers, with a growing percentage of English-speaking students enrolling here (and a large percentage that has already enrolled - approximately $40 \%$ ). We therefore conclude that even though we fully realise that it may not be possible to generalise our findings to other universities, we nevertheless believe that our findings have relevance for the Faculties of Education at all other South African universities.

Scrutiny of Table 4 indicates that the vast majority of students enrolling at UP originate from urban centres.

Next the frequency distribution of the merit scores obtained in Grade 11 or 12 (as indicated by the respondents) is set out and discussed in Table 5.

From Table 5 it is clear that the largest percentage of students obtained a merit score of between 13 and 18 (both 13 and 18 included). These results correlate with those of Cosser and Du Toit (2002), who rightly emphasise how important it is that the quality of education in general should be improved in order to help especially those students with an African home language to perform better at the end of Grade 12. The intention is to facilitate 
TABLE 5

Frequency distribution: Merit score obtained $(\mathrm{n}=442)$

\begin{tabular}{lrrcc}
\hline Merit score & Frequency & Percentage & $\begin{array}{c}\text { Cumulative } \\
\text { frequency }\end{array}$ & $\begin{array}{c}\text { Cumulative } \\
\text { percentage }\end{array}$ \\
\hline $25-30$ & 25 & 5.66 & 25 & 5.66 \\
$19-24$ & 119 & 26.92 & 144 & 32.58 \\
$13-18$ & 169 & 38.24 & 313 & 70.82 \\
$7-12$ & 126 & 28.51 & 439 & 99.33 \\
Not indicated & 3 & 0.67 & 442 & 100.00 \\
\hline
\end{tabular}

the entrance of African language speaking Grade 12 learners into a tertiary institution and to ensure better representation of African language speaking students inter alia in the teaching disciplines. This view is also supported by the Department of Education (2002).

\section{Procedure}

The Questionnaire to First-year Student Teachers was filled in at a single session of the orientation programme of the Faculty of Education of the University of Pretoria in January 2004. The completed questionnaires were subsequently coded and analysed with the assistance of the Department of Statistics (University of Pretoria). The data was presented in two ways, namely descriptive and inferential.

\section{Assessment instrument}

The questionnaire designed for the purposes of the current investigation was compiled on the basis of an in-depth study of the literature, after which it was submitted to a number of education experts for critical commentary. The comments obtained were considered by the compilers of the questionnaire and a number of changes were made. 


\section{Limitations of the study}

Some of the limitations of the study are the following:

- The scope of the study was limited.

- No standardised questionnaires were used in the research.

- The research group was limited to UP students, and therefore statistical inference or generalisation is limited to students attached to the Faculty of Education, UP. Generalisation of the results would therefore not be valid for Gauteng or for SA; such an exercise would require a more comprehensive survey.

- Another researcher could well interpret the results in a different manner.

\section{Ethical aspects}

The appropriate University authorities as well as Faculty authorities and students were liaised with and written permission was obtained prior to the gathering of any information by means of the questionnaire. Students were informed about the aim of the research project and they were requested to give their permission for the publication of the research results.

\section{Research questions and hypotheses; data procedure, instruments and processing}

\section{Research hypotheses ${ }^{3}$}

The main hypothesis investigated in the study concerned the possible reasons why first-year teacher students decide on teaching as a career, as well as the possible relationships between a variety of factors that play a role in the career choice of the 2004 first-year teacher students attached to the University of Pretoria and their choice of teaching as a profession.

The secondary research hypotheses focus in general on the relationships between the different factors that exert an influence on first-year teacher students' decision about teaching as a possible career. The effect of the following independent variables was investigated:

${ }^{3}$ For the aim of this study, the $5 \%$ level of significance was used. 
- Gender

- Age

- Mother tongue

The null hypothesis ${ }^{4}$ was formulated:

- $\mathrm{H}_{\mathrm{o} 1}$ : The merit scores of the gender groups do not differ significantly (Table 6).

- $\mathrm{H}_{\mathrm{o} 2}$ : The merit scores of the mother tongue groups do not differ significantly (Table 7).

- $\mathrm{H}_{\mathrm{o}}$ : The income of the mother tongue groups do not differ significantly (Table 8).

- $\mathrm{H}_{\mathrm{o} 4}$ : The performance of males and females in the four fields of the Questionnaire to First-Year Teacher Students do not differ significantly (Table 15).

- $\mathrm{H}_{\mathrm{o5}}$ : There is no significant difference between the relative influence of others on the career choice of first-year students (Table 16).

In an effort to investigate the research questions and hypotheses, the following statistical calculations were made:

\section{Descriptive statistics}

The following descriptive details were determined.

- The frequency distribution of the total group with regard to aspects such as gender, merit score, income, home language, as well as geographic location of the parental home.

- Where applicable, the averages and standard deviations in respect of relevant variables.

\section{Inferential statistics}

A number of inferential statistical procedures were performed in order to examine the hypotheses concerned. These procedures included the following:

a) An item analysis on the questionnaire completed by the students.

b) Factor analysis (Varimax rotation) on the items of the questionnaire in order to examine the underlying pattern or relationships between the variables.

${ }^{4}$ For the sake of conciseness, alternative hypotheses have been omitted. 
c) Reliability coefficient: Cronbach's alpha coefficient for the questionnaire as a whole, as well as for the items comprising each factor identified by the factor analysis.

d) Pearson correlation coefficients.

e) Confidence intervals.

f) Wilcoxon Rank Sum Test.

g) One-way analysis of variance.

\section{RESULTS}

\section{Confidence intervals}

Table 6 provides confidence intervals for a comparison of the merit scores of gender groups.

It appears from Table 6 that the mean merit scores of first-year male and female students differ significantly in favour of the latter. Thus, it seems that male first-year students who enrolled at UP's Faculty of Education for the first time in 2004 had achieved significantly weaker at school than their female counterparts. It can therefore be deduced that men who perform well at school rather tend to enrol for study areas other than teaching (in this case the following arbitrary criterion was used as an indicator of a relatively good performance: merit score $>16$ ).

\section{TABLE 6}

Confidence intervals for a comparison of the merit scores of gender groups $\left(\mathrm{n}_{\text {male }}=100 ; \mathrm{n}_{\text {female }}=338\right)$.

\begin{tabular}{lcccc}
\hline $\begin{array}{l}\text { Mean merit score for } \\
\text { gender group }\end{array}$ & $\bar{x}$ & Index value & \multicolumn{2}{c}{$\begin{array}{c}\text { 95\% confidence } \\
\text { interval }\end{array}$} \\
\cline { 4 - 5 } & & & $\begin{array}{c}\text { Lower } \\
\text { limit }\end{array}$ & $\begin{array}{c}\text { Upper } \\
\text { limit }\end{array}$ \\
\hline Male students & 13.70 & a & 12.81 & 14.59 \\
Female students & 16.80 & a & 16.23 & 17.36 \\
\hline
\end{tabular}

Mean scores with the same index values differ significantly from one another at the $5 \%$ level $(p<0.05)$. 
Table 7 shows that the 'other' students (i.e. students who have neither Afrikaans, English or an African language as home language) achieved the highest average merit score, followed by English-speaking first-year students, Afrikaans-speaking students and students with an African language as mother language. The merit score of the latter group of students was significantly lower than that of the other home language groups (at the 5\% level of significance). Experience has taught that these students initially struggle to adjust in extremely disruptive, almost foreign circumstances, but after a period of some months tend to find their feet and achieve much better performances than their inadequate merit score might suggest (Maree, 2005). A further inference that may be made is that those students who have an African language as their home language and who perform well, generally do not tend to choose teaching as a possible career.

The confidence intervals for comparing the income of different language groups will be explained and discussed.

It transpires from Table 8 that the income of the parents of students with an African language as home language was significantly lower than the average income of all the other groups (at the $5 \%$ level of significance). This finding supports

TABLE 7

Confidence intervals for comparing the merit scores of language

$$
\begin{gathered}
\text { groups }\left(\mathrm{n}_{\text {English }}=85 ; \mathrm{n}_{\text {Afrikaans }}=308 ;\right. \\
\left.\mathrm{n}_{\text {African languages }}=38 ; \mathrm{n}_{\text {Other }}=8\right)
\end{gathered}
$$

\begin{tabular}{lcccc}
\hline $\begin{array}{c}\text { Mean score of } \begin{array}{c}\text { mother tongue } \\
\text { group }\end{array} \\
\text { m }\end{array}$ & $\bar{x}$ & Index value & \multicolumn{2}{c}{$\begin{array}{c}\text { 95\% confidence } \\
\text { interval }\end{array}$} \\
\cline { 4 - 5 } & & & $\begin{array}{c}\text { Lower } \\
\text { limit }\end{array}$ & $\begin{array}{c}\text { Upper } \\
\text { limit }\end{array}$ \\
\hline English & 16.77 & $\mathrm{a}$ & 15.87 & 17.68 \\
Afrikaans & 13.32 & $\mathrm{~b}$ & 15.71 & 16.93 \\
African languages & 11.87 & $\mathrm{ab}$ & 10.57 & 13.16 \\
Other & 20.00 & $\mathrm{~b}$ & 17.06 & 22.94 \\
\hline
\end{tabular}

Mean scores with the same index values differ significantly from one another at the $5 \%$ level $(p<0.05)$ 


\section{TABLE 8}

Confidence intervals for comparing the income of language

$$
\begin{gathered}
\text { groups }\left(\mathrm{n}_{\text {English }}=62 ; \mathrm{n}_{\text {Afrikaans }}=249 ;\right. \\
\left.\mathrm{n}_{\text {African languages }}=27 ; \mathrm{n}_{\text {Other }}=6\right)
\end{gathered}
$$

\begin{tabular}{lcccc}
\hline \multicolumn{1}{c}{$\begin{array}{c}\text { Mean income of } \\
\text { language group }\end{array}$} & $\bar{x}$ & Index value & \multicolumn{2}{c}{$\begin{array}{c}95 \% \text { confidence } \\
\text { interval }\end{array}$} \\
\cline { 3 - 5 } & & & $\begin{array}{c}\text { Lower } \\
\text { limit }\end{array}$ & $\begin{array}{c}\text { Upper } \\
\text { limit }\end{array}$ \\
\hline English & 146854.34 & a & 119821.97 & 173886.70 \\
Afrikaans & 189999.50 & a & 178524.44 & 201474.56 \\
African & 69629.13 & ab & 38794.03 & 100464.22 \\
languages & & & & \\
Other & 166666.17 & b & 136548.99 & 196783.35 \\
\hline
\end{tabular}

Mean scores with the same index values differ significantly from one another at the $5 \%$ level $(p<0.05)$

that reached by authors such as Maree (2005), Maree, Aldous, Hattingh, Swanepoel and van der Linde (2006), Maree and Molepo (1999), as well as Mkhize (2004) and others, who express their concerns about the inadequate socioeconomic circumstances in which the vast majority of black students find themselves.

\section{Factor analysis}

The factor analysis was performed by means of the $\mathrm{SAS}^{\circledR}$ computer software program $\left(\mathrm{SAS}^{\circledR}\right.$, version 8.2 , VM/ESA, 2004), using a orthogonal varimax or oblique procrustes rotation method in order to determine the underlying dependency with regard to the different items as reflected by the V15-V43 (see Appendix 1). A scree plot determined that three or four possible factors were present. Four independent fields (factors) were identified within which the respective elements correlated strongly with one another. In order to improve the correlations, a decision was taken to omit Item 20 (V20), which had a loading 
of between 0.22 and -0.21 over the four factors. Correlations between the items in Field 1 subsequently increased. The factor analysis explained the underlying relationship between the different variables. Since the fields all had eigenvalues larger than one, they could be interpreted.

The following four fields were identified by means of the varimax rotation method:

Factor 1: Potential facilitation in teaching

Factor 2: $\quad$ Fringe benefits

Factor 3: $\quad$ Financial considerations

Factor 4: Discernible obstacles

(See Table 9 for a description of the numbers as well as the questions of the variables concerned.)

Table 9 presents the final factor loading per item, as well as the eigenvalues for each field of the Questionnaire.

All the eigenvalues of the principal factors were larger than one (1). This implies that these factors were valid and could be interpreted. Table 9 furthermore shows that all of the 32 selected items in fact belonged to the four fields.

\section{Item analysis}

An item analysis was performed on the final 32 selected items that had been categorised into the four fields in order to determine the merit of the final fields. A minimum inclusion value of 0.30 was set for the purpose of this study. ${ }^{5}$

An item scale analysis is presented in Table 10.

It is clear from Table 10 that all the discrimination values were $\geq 0.30$, except for V42 that was 0.25 and VV33 (=V33 reversed) that was 0.19 . All of the reliability coefficients were $\geq 0.5$, which implies that the composition of the factors was valid.

\footnotetext{
${ }^{5}$ According to Nunnally (in Owen, 1995), the researcher's opinion regarding including or excluding certain items may be regarded as decisive if including these items can be justified on logical grounds (which is exactly the case in the research that is being reported here).
} 


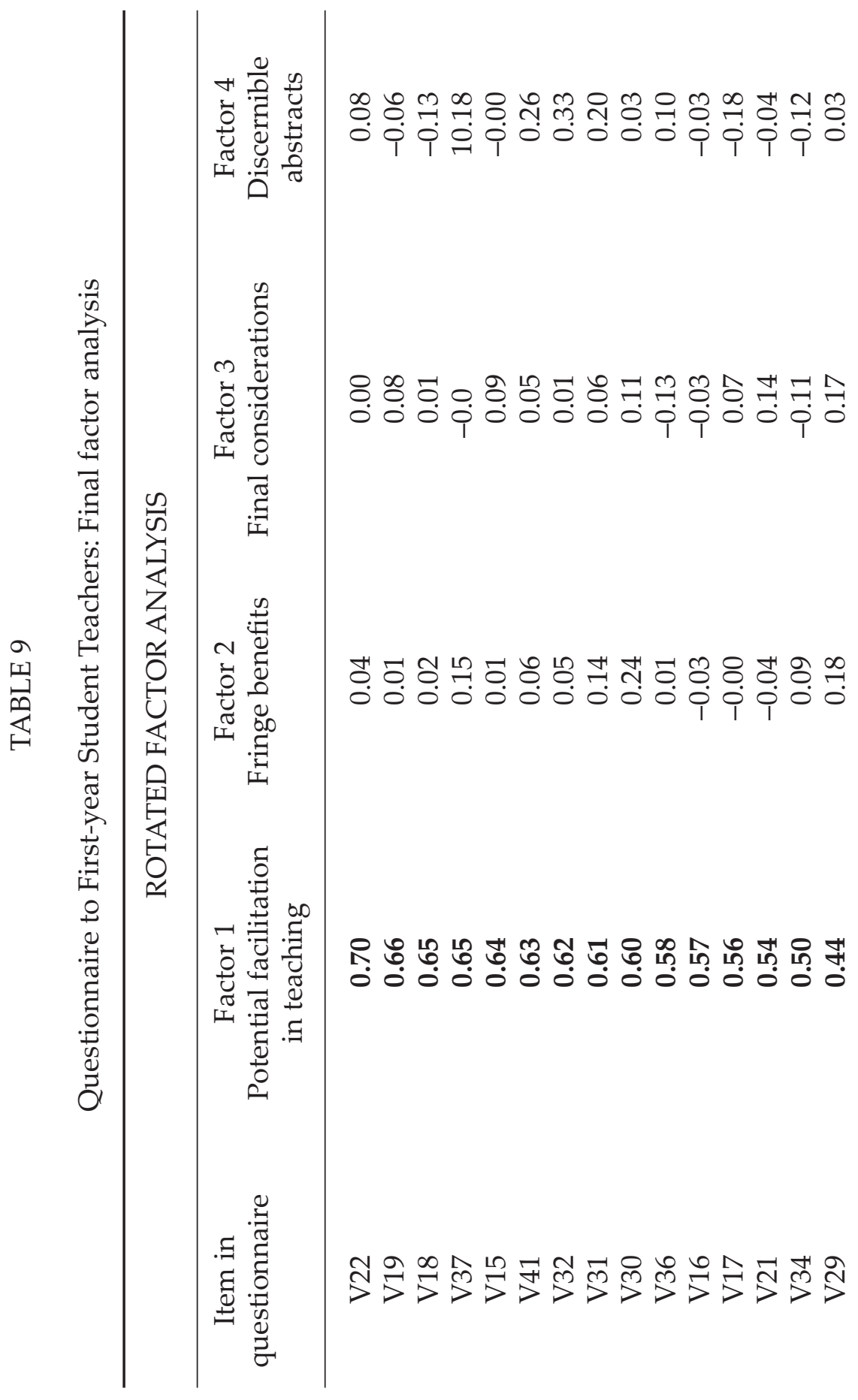




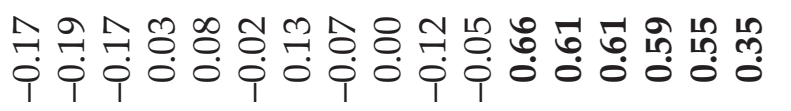

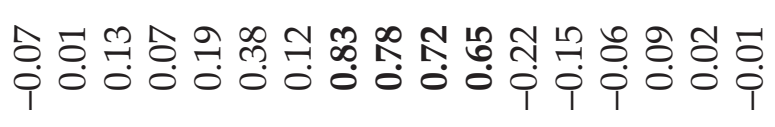

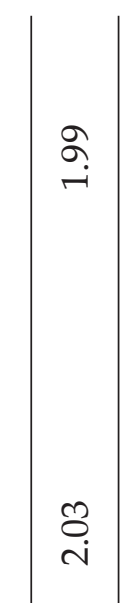

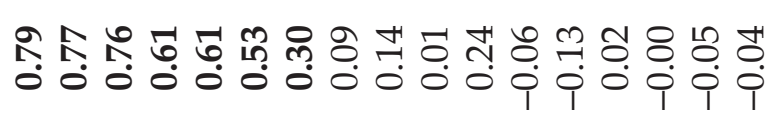

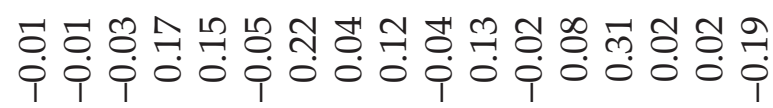

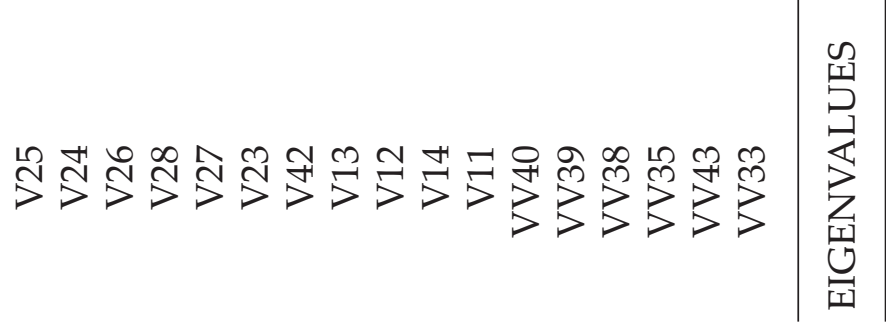

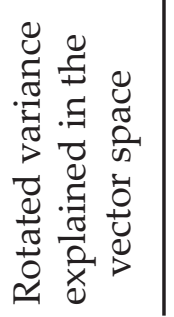


TABLE 10

Item scale analysis and reliability

\begin{tabular}{ccc}
\hline \multicolumn{3}{c}{ Factor 1: Potential facilitation in teaching ${ }^{6}$} \\
\hline Item numbers & Correlation of item with total & Alpha \\
\hline V15 & 0.55 & 0.86 \\
V16 & 0.45 & 0.86 \\
V17 & 0.45 & 0.86 \\
V18 & 0.54 & 0.86 \\
V19 & 0.57 & 0.86 \\
V21 & 0.45 & 0.86 \\
V22 & 0.62 & 0.86 \\
V29 & 0.42 & 0.87 \\
V30 & 0.57 & 0.86 \\
V31 & 0.56 & 0.86 \\
V32 & 0.57 & 0.86 \\
V34 & 0.40 & 0.86 \\
V36 & 0.51 & 0.86 \\
V37 & 0.60 & 0.85 \\
V41 & 0.57 & 0.86 \\
\hline & Factor 2: Fringe benefits & \\
\hline Item numbers & Correlation of item with total & Alpha \\
\hline V23 & 0.49 & 0.76 \\
V24 & 0.61 & 0.74 \\
V25 & 0.58 & 0.74 \\
V26 & 0.66 & 0.73 \\
V27 & 0.53 & 0.76 \\
V28 & 0.47 & 0.80 \\
V42 & 0.25 & \\
\hline
\end{tabular}

continued over

${ }^{6}$ On advice of the statisticians, the questions falling under Factors 1, 2, and 3 were formulated in such a way that a positive construct could be named. Factor 4 , in turn, was a negative construct. 
Table 10 continued

Factor 3: Financial considerations

\begin{tabular}{ccc}
\hline Item numbers & Correlation of item with total & Alpha \\
\hline V11 & 0.53 & 0.78 \\
V12 & 0.67 & 0.71 \\
V13 & 0.70 & 0.71 \\
V14 & 0.55 & 0.78 \\
\hline
\end{tabular}

Factor 4: Discernible obstacles

\begin{tabular}{ccc}
\hline Item numbers & Correlation of item with total & Alpha \\
\hline VV33 & 0.19 & 0.62 \\
VV35 & 0.33 & 0.55 \\
VV38 & 0.36 & 0.55 \\
VV39 & 0.39 & 0.52 \\
VV40 & 0.49 & 0.50 \\
VV43 & 0.31 & 0.56 \\
\hline
\end{tabular}

TABLE 11

Cronbach's $\alpha$ coefficient for the Questionnaire to First-year Student Teachers

\begin{tabular}{ccccc}
\hline & Factor 1 & Factor 2 & Factor 3 & Factor 4 \\
\hline$\alpha$ coefficient & 0.87 & 0.79 & 0.80 & 0.60 \\
\hline
\end{tabular}

\section{Reliability coefficients}

The reliability coefficients of the four fields of the Questionnaire were determined by means of Cronbach's $\alpha$ coefficient.

The reliability coefficients varied between 0.60 and 0.85 (see Table 11) and may be regarded as highly satisfactory for the purposes of the current study. 
TABLE 12

Inter-field correlations of the four factors in the Questionnaire to First-year Student Teachers

\begin{tabular}{ccrrr}
\hline Factors & 1 & 2 & 3 & 4 \\
\hline 1 & 1.00000 & & & \\
2 & 0.16412 & 1.00000 & & \\
3 & 0.12353 & 0.25121 & 1.00000 & \\
4 & 0.21170 & -0.10220 & -0.09824 & 1.00000 \\
\hline
\end{tabular}

\section{Pearson correlation coefficients for the various groups}

\section{Pearson correlation coefficients}

Table 12 presents the intercorrelations of the fields in the Questionnaire to First-year Student Teachers for the whole group. These values reflected low correlations between fields, which were ideal, because it showed that the items in the respective fields measured different aspects that had a bearing on the choice of teaching as a career.

Table 13 provides the Pearson correlation coefficients across the four fields for male first-year teacher students.

From Table 13 it can be gathered that for males there was a statistically significant correlation between field 1 (Potential facilitation in teaching, or the opportunity that teaching offers students to actualise their potential to the full) and 2 (Fringe benefits); field 1 (Potential facilitation in teaching) and 3 (Financial considerations), as well as fields 2 (Fringe benefits) and 3 (Financial considerations). These correlations were positive, which implied that the values of the fields would move in the same directions, for example, should fringe benefits increase, financial considerations would also increase and vice versa.

Table 14 sets out the results of Pearson correlation coefficients across the four fields for female first-year teacher students.

Table 14 shows a statistically significant correlation between field 1 (Potential facilitation in teaching) and 2 (Fringe benefits); field 1 (Potential facilitation in teaching) and 3 (Financial considerations), as well as fields 2 (Fringe benefits) and 3 (Financial considerations). These correlations were positive, 
TABLE 13

Results of the Pearson correlation coefficients of the four fields for males

\begin{tabular}{llllrl}
\hline & & Field 1 & Field 2 & Field 3 & Field 4 \\
\hline \multirow{3}{*}{ Males } & Field 1 & 1.00000 & & & \\
& Field 2 & $0.40778^{*}$ & 1.00000 & & \\
& Field 3 & $0.35962^{*}$ & $0.41492^{*}$ & 1.00000 & \\
& Field 4 & 0.10581 & 0.02966 & -0.01854 & 1.00000 \\
\hline
\end{tabular}

$*: p<0.05$

which implied that the values of the fields would move in the same directions, for example, should fringe benefits increase, financial considerations would also increase and vice versa. In the case of fields 2 (Fringe benefits) and 4 (Discernible obstacles), as well as fields 3 (Financial considerations) and 4 (Discernible obstacles), the correlations were negative, which indicated that the values of the fields would move in opposite directions, for example, if fringe benefits were to increase, discernible obstacles would decrease and vice versa.

TABLE 14

Results of the Pearson correlation coefficients of the four fields for females

\begin{tabular}{llllll}
\hline & & Field 1 & Field 2 & Field 3 & Field 4 \\
\hline & Field 1 & 1.00000 & & & \\
Females & Field 2 & $0.21679^{*}$ & 1.00000 & & \\
& Field 3 & $0.12109^{*}$ & $0.29768^{*}$ & 1.00000 & \\
& Field 4 & 0.00688 & $-0.19763^{*}$ & $-0.15695^{*}$ & 1.00000 \\
\hline
\end{tabular}

$*: p<0.05$ 


\section{Comparison between the performance of the two gender groups in the four fields of the Questionnaire to First-year Student Teachers}

Table 15 presents the subcategories of gender and the various fields (as identified by the factor analysis).

(Effect sizes were important here, as the scale of measurement was not meaningful to researchers. For income and $\mathrm{M}$ score the scale was known and researchers knew when a difference was large enough to be of practical importance; then only $\mathrm{p}$ needed to be given. Here that was not the case.)

It appears from Table 15 that the mean scores for males and females with regard to Field 1 (Potential facilitation in teaching), field 3 (Financial considerations) and field 4 (Discernible obstacles) differed statistically significantly.

The following deductions could possibly be made from Table 15

- Females were more inclined to attach value to personal development as a co-determining factor in the choice of teaching as a career (field 1). However, the result was not practically significant.

- Females were more inclined to attach value to discernible obstacles as a co-determining factor in the choice of teaching as a career (field 4). The size of the difference was large enough to be conspicuous $(\mathrm{d}=0.57$, in other words, a medium effect size), which seemed to indicate that females had a higher

\section{TABLE 15}

Results of the Wilcoxon Rank Sum Test* when comparing the performance of gender groups in the respective fields $(n=101)$

\begin{tabular}{lcccccc}
\hline & \multicolumn{2}{c}{ Males } & \multicolumn{2}{c}{ Females } & \multirow{2}{*}{ p-value $\begin{array}{c}\text { d-value } \\
\text { (effect size) }\end{array}$} \\
\cline { 2 - 5 } & $\bar{x}$ & $\mathrm{~s}$ & $\bar{x}$ & $\mathrm{~s}$ & & \\
\hline Field 1 & 3.88 & 0.66 & 4.13 & 0.53 & $0.0008^{* *}$ & 0.38 \\
Field 2 & 2.91 & 0.91 & 2.74 & 0.88 & 0.1035 & 0.19 \\
Field 3 & 2.38 & 1.27 & 2.05 & 1.04 & $0.0446^{* *}$ & 0.26 \\
Field 4 & 3.56 & 0.61 & 3.91 & 0.54 & $<0.0001^{* *}$ & 0.57 \\
\hline
\end{tabular}

*: Data was not distributed normally - hence a distribution-free test was used. $* *: p<0.05$ 
average score than males, yet the result was not practically highly significant.

- Males, on the contrary, were more inclined to attach value to financial considerations as a co-determining factor in the choice of teaching as a career (field 3). The result was not practically significant.

A comparison of the influence of role models on the career choice of first-year teacher students was then examined.

It appears from Table 16 that parents were considered to be the most important role models. The difference was large enough to be conspicuous ( $\mathrm{d}=0.54$, in other words a medium effect size), which could imply that parents were considered more important than other educators, but the result was not practically highly significant.

Our findings confirm the findings of Turner and Lapan (2002) and Cosser and Du Toit (2002), who also emphasise the importance of parents as role models in the career choice of their children. It was particularly alarming to observe that, in the current study, the school principal and career guidance teacher did not figure prominently in students' choice of teaching as a career.

\section{SUMMARY AND RECOMMENDATIONS}

The analyses presented in this paper show inter alia that various factors affect the career choice of first-year teacher students, namely Factor 1: Potential facilitation in teaching (in other words the opportunity that teaching offers students to actualise their potential to the full), Factor 2: Fringe benefits, Factor 3: Financial considerations, as well as Factor 4: Discernible obstacles.

We would also like to highlight the following four trends that emerged from the study in hand.

a. Far fewer males than females enter teaching as a career.

b. In the Faculty of Education at UP relatively few students with an African language as home language select teaching as a career. At English-medium training institutions, the situation may perhaps differ.

c. A small minority of student teachers (5.66\%) fall in the category of top achievers. An educationally meaningful percentage of 


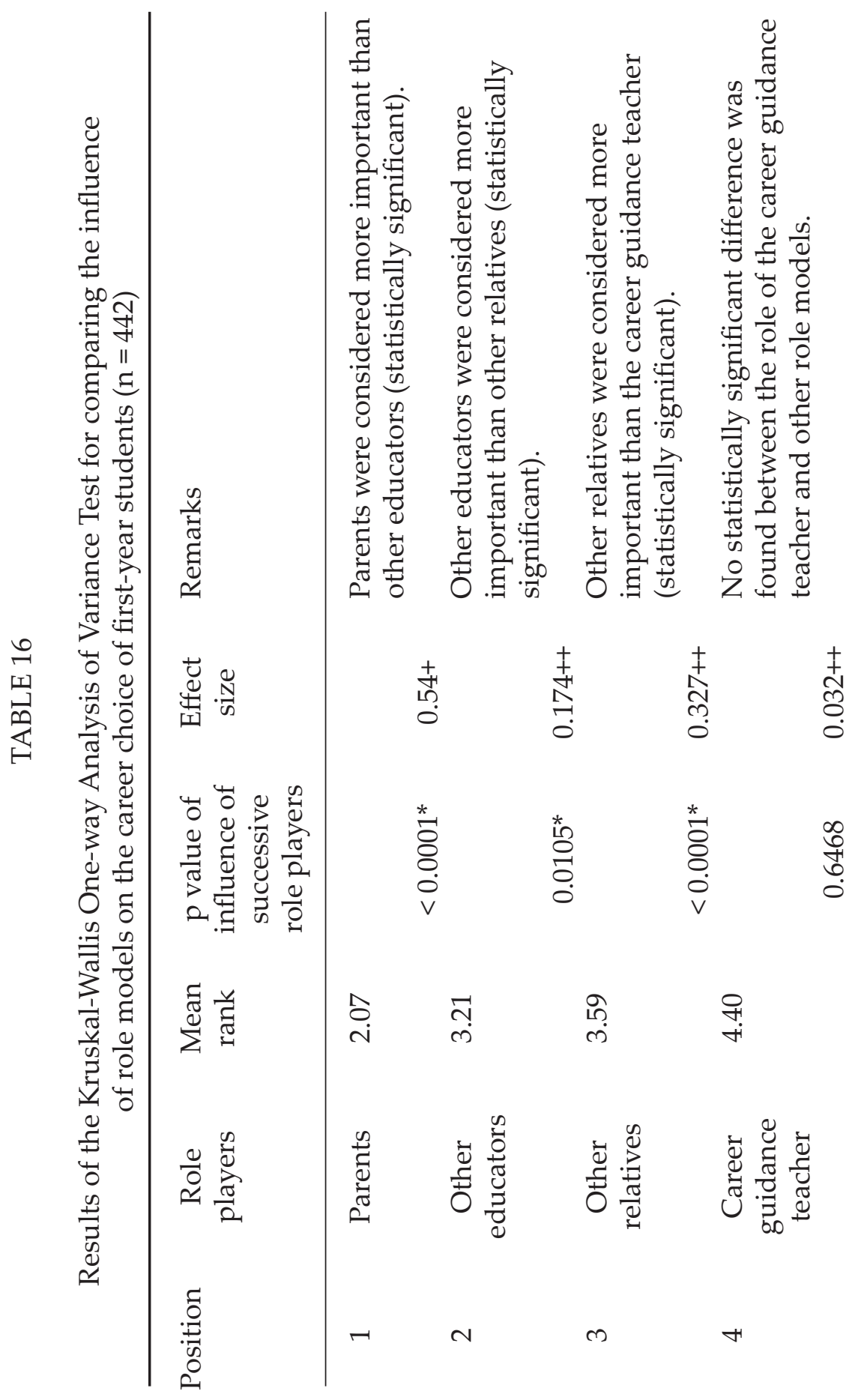




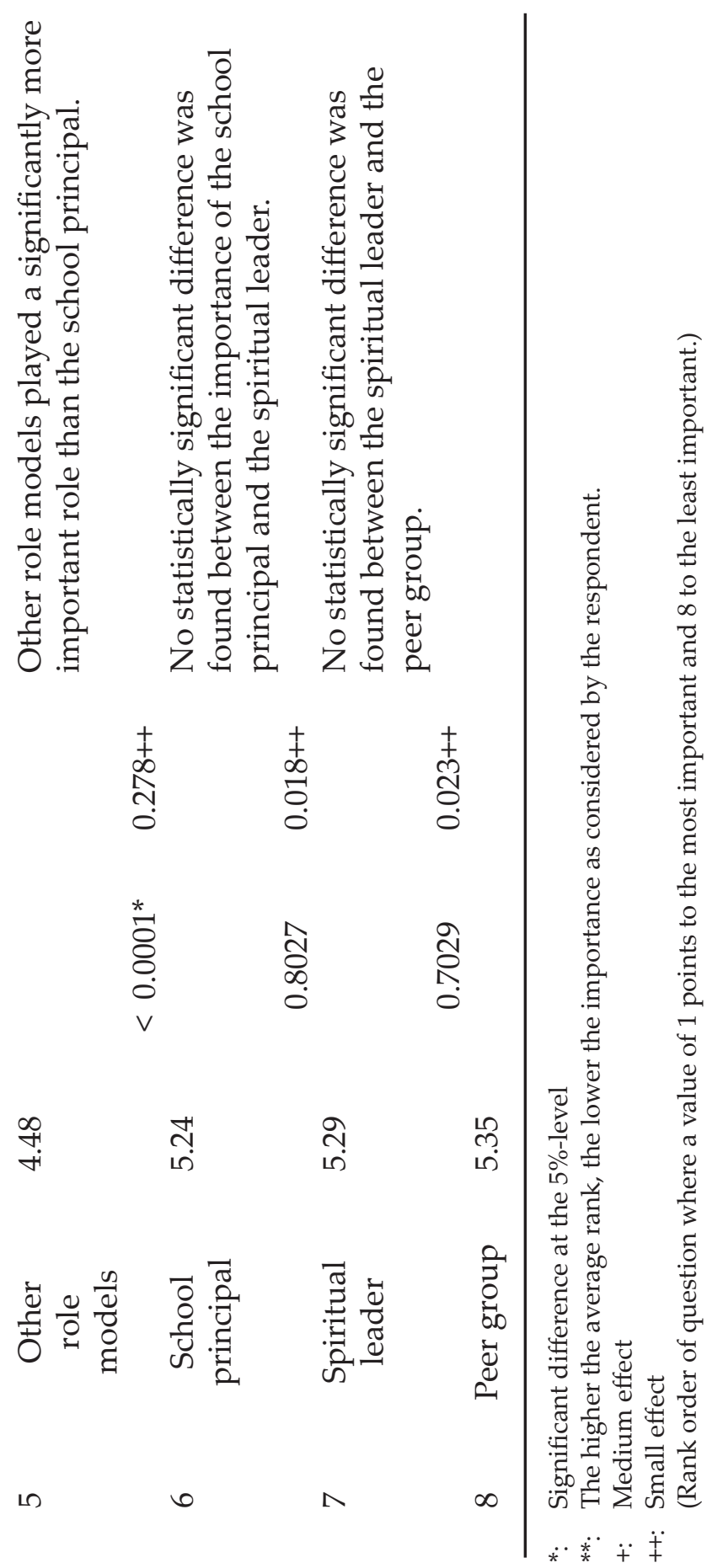


66

students (28.51\%) obtained particularly low M scores, whereas the majority of students fell in the average to above average group.

d. The role of parents in the career choice of their children can never be underestimated.

These facets clearly deserve the attention of all concerned.

In a similar vein, Chapman (1984) refers to the role played by significant others (parents, teachers, the peer group as well as special friends) in the career choice of children. Cosser and $\mathrm{Du}$ Toit (2002) agree with these findings and refer to the case of speakers of African languages, where these significant others play an invaluable role in career choice. Epistomologically the results of this study therefore also link up with the Social Cognitive Career Theory and confirm inter alia the direct relationship between the career choice of first-year teacher students and the support of significant others. In this respect, Lent, Brown and Hackett (1996), as well as Turner and Lapan (2002), support the following view:

\footnotetext{
"[This theory] provides a model for understanding how the perceived support of parents and the confidence gained through student participation in comprehension guidance programs interact to support the career development of adolescents (p. 44)."
}

Lent et al. (1966) also refer to other aspects, such as background, ethnicity, race and contextual factors that influence career choice.

In conclusion, we focus on a number of recommendations.

i. Inter-institutional research could possibly be conducted in order to determine the factors that may influence firstyear teacher students to select teaching as a career at different training institutions. A longitudinal survey could be performed in which the results of the Questionnaire to First-year Student Teachers may be compared to a similar questionnaire (or an adapted version of this questionnaire) that may be administered during the third or fourth year of study.

ii. The making of career choices by adolescents should receive more serious attention. The gathering of information about possible occupations as well as (e.g.) the implications of choosing a specific career may contribute to the decisionmaking process. Sometimes a detailed exposition of what exactly teaching entails as a career is considered to be of 
trivial importance. Yet this information is crucial and should be made available to both prospective and non-prospective teachers at a national level.

iii. Road shows as government initiatives should be directed at empowering both parents and adolescents with regard to teaching as a career. Adequate information on teaching as a career should be made available at these events.

iv. Moreover, the influence of parents on the career decisionmaking process should never be disregarded. The marketing of teaching as a career should therefore - to a greater extent be aimed at parents. The results obtained during the qualitative part of our research still show that parents often make career decisions on behalf of adolescents. Therefore parents should be involved in the career decision-making process to a much larger degree, but the ultimate career decision should be left to the adolescent. Parents are still considered to be among the most important role models in the process and should receive in-depth guidance to understand the implications of teaching as a career.

v. The potential influence of the career guidance teacher on the career choice of the adolescent may not be ignored. Cosser and Du Toit (2002) recommend that the Department of Education:

"Should thus increase its support for career counselling initiatives in schools - particularly where learners are not in a position, or feel themselves unable, to discuss their future plans with parents or guardians (p. 14)."

We therefore recommend that further research should be conducted on the role played by the career guidance teacher in respect of the career choice of learners. This view is based inter alia on the following quotation by Cosser and Du Toit (2002):

"A higher percentage of learners having received some career guidance rather than not having received any such guidance intended entering higher education (79\% versus 60\%) (p. 14)."

Currently practising teachers could perhaps receive more adequate support, among other in the sense that better, as well as additional fringe benefits and incentives should be negotiated.

Lastly, we refer to the following facets of the self-concept theory of Super (Maree, 2002): Career choice and adjustment is an ongoing process that includes the following: growth, exploration, development, maintenance and deterioration. Career patterns in 
particular are co-determined inter alia by a) the configuration of personality traits, b) opportunities and c) career maturity. The extent to which a person's personality traits (including skills, needs, values, interests and self-concept) are actualised influences his/her career satisfaction as well as satisfaction in general. In view of current complications in the field of education (including the current strikes and unpleasant conflict between education authorities and trade union leaders), we are expressing our serious concern about the way in which teachers have been treated for many years, and also about the impact of perceptions of the teaching profession that have been established over time, but especially about the potentially extremely negative impact of the above on career choice trends in South Africa, with specific reference to the inadequate and ever-shrinking number of Grade 12 school-leavers entering the career. To quote Jansen (2006):

"When teacher role models no longer exist, there can be no competent doctors or inspired poets or dedicated social workers or competent citizens. In fact, there can no longer be good schools. When that happens, there can no longer be democratic societies."

\section{REFERENCES}

Arthur, N. \& McMahon, M. (2005). Multicultural career counselling: Theoretical applications of the systems theory framework. Career Development Quarterly, 53(13), 208-223.

Betz, N.E. (1989). The null environment and women's career development. Counselling Psychologist, 17, 136-144.

Butcher, J. \& Lewis, E. (2003). Teaching: An appealing choice to school leavers? Paper presented at AARE Conference, Sydney. Accessed: 30 July 2005, at http://www. iconline.org/feature_articles/f4_03.htm

Chapman, D.W. (1984). Teacher retention: The text of a model. American Education Research Journal, 21(3), 645-652.

Chisholm, L. (2004). Introduction. Changing class: Education and social change in postapartheid South Africa. (Chisholm, L. ed.) pp. 1-27. HSRC Press; Cape Town.

Cook, E.P., Heppner, M.J. \& O’Brien, K.M. (2002). Career development of women of color and white women: Assumptions, conceptualisation, and interventions from an ecological perspective. The Career Development Quarterly, 50, 291-305.

Cosser, M. \& Du Toit, J. (2002). Factors affecting student choice behaviour in the course of secondary education with particular reference to entry into higher education. Research Report. HSRC; Pretoria.

Crouch, L. (2001). Turbulence or orderly change? Teacher supply and demand in the age of AIDS. Department of Education; Pretoria.

Crouch, L. \& Perry, H. (2003). Educators. In Human resources development review: Education, employment and skills in South Africa. (Kraak, A. \& Perold, H., eds). Accessed: 8 April 2004, at www.unesco.org/.../file_download.php. 
Department of Education. (2001). National plan for higher education. Department of Education; Pretoria.

Department of Education. (2002). Annual Report 2002/2003. Government Printers; Pretoria.

Fouad, N.A. \& Byars-Winston, A.M. (2005). Cultural context of career choice: Meta-analysis of race/ethnicity differences. Career Development Quarterly, 53: 223-233.

Hislop-Esterhuizen, N. (2006). Some factors that influence the career choice of first-year student teachers. (Enkele faktore wat die beroepskeuse van eerstejaaronderwysstudente beïnvloed.) Unpublished Master's degree dissertation. Pretoria: University of Pretoria.

Human Sciences Research Council. (2005). Study of demand and supply of educators in South Africa. Education Labour Relations Council. Media releases 2005. Accessed: 13 April 2005, at http://www.hsrc.ac.za/media/2005/3/20050331. html.

Jansen, J. (2006). Interview granted to authors.

Lent, R.W., Brown, S.D. \& Hackett, G. (1996). Career development from a social cognitive perspective. (pp. 373-421). In Career choice and development 3rd ed. (Brown, D. \& Brooks, L. eds). Jossey-Bass; San Francisco.

Maree, J.G. \& Molepo, J.M. (1999). The role of mathematics in developing rural and tribal communities in South Africa. South African Journal of Education, 19(4), 374-381.

Maree, J.G. (2002). Theoretical approaches: An overview. 2002. In Lifeskills and career counselling Maree, J.G. \& Ebersöhn, L. eds. pp. 1-32). Heinemann Publishers; Cape Town.

Maree, J.G. (2005). The torn learning sprockets: stars in the ascendant. Gifted Education International, 20(2), 112-122.

Maree, J.G., Aldous, C., Hattingh, A., Swanepoel, A. \& van der Linde, M.J. (2006). Predictors of learner performance in mathematics and science according to a large-scale study in Mpumalanga. South African Journal of Education, 26(3), $229-252$.

Mkhize N. (2004). Social transformation and career marginalisation: theoretical and research implications. Paper read at the 10th Anniversary of the South African Congress of Psychology: Democratising the psyche, Durban, 20-23 September 2004.

Ngidi, D.P. \& Sibaya, P.T. (2002). Black teachers' personality dimensions and workrelated stress factors. South African Journal of Psychology, 32(3), 7-15.

Osipow, S.H. (1983). Theories of career development (2nd ed.). In 2005. Multicultural career counselling: Theoretical applications of the systems theory framework. Career Development Quarterly, Arthur, N. \& McMahon, M. 53(13), 208-223.

Parker, R. (2004). Immigration brain drain. Accessed: 3 March 2005, at http://www. parapundit.com/archives/002014.html.

Pretorius, C. \& Heard, J. (2002). Shock teacher shortage looms: Dramatic fall in enrolments at training institutions will trigger education crisis within two years. Accessed: 3 July 2004, at http://www.aegis.com/news/suntimes/1999/ST990503. htm 
Quimby, J.L. \& O'Brien, K.M. (2004). Predictors of student and career decisionmaking self-efficacy among non-traditional college women (Career counseling). Career Development Quarterly, 52(14), 323-340.

Quinn, A. (2005). Reuters foundation: Alerting humanitarians to emergencies. Aids blamed as S. Africa reports huge jump in deaths. Accessed: 9 March 2005, at: http://www.alertnet.org/printable.htm?URL=/thenews/newsdesk/L18300128. htm.

Royal Society of South Africa. (2003). News Bulletin. Accessed: 8 April 2004 at WwW. royalafricansociety.org

SAS Institute Inc. (2004). SAS STAT User's Guide, Version 8.2, Cary, NC: SAS Institute Inc.

Splete, N. \& Freeman-George, N. (1985). In Naylor, M. (1986). Family influences on employment and education. Overview. Eric Digest No. 56. Eric database. (Accessed: 8 November 2003).

Turner, S. \& Lapan, R.T. (2002). Career self-efficacy and perceptions of parent support in adolescent career development. Career Development Quarterly, 51(1), $44-55$.

Vermeulen, P. (2008). Personal communication to the authors in 2008. 


\section{APPENDIX 1}

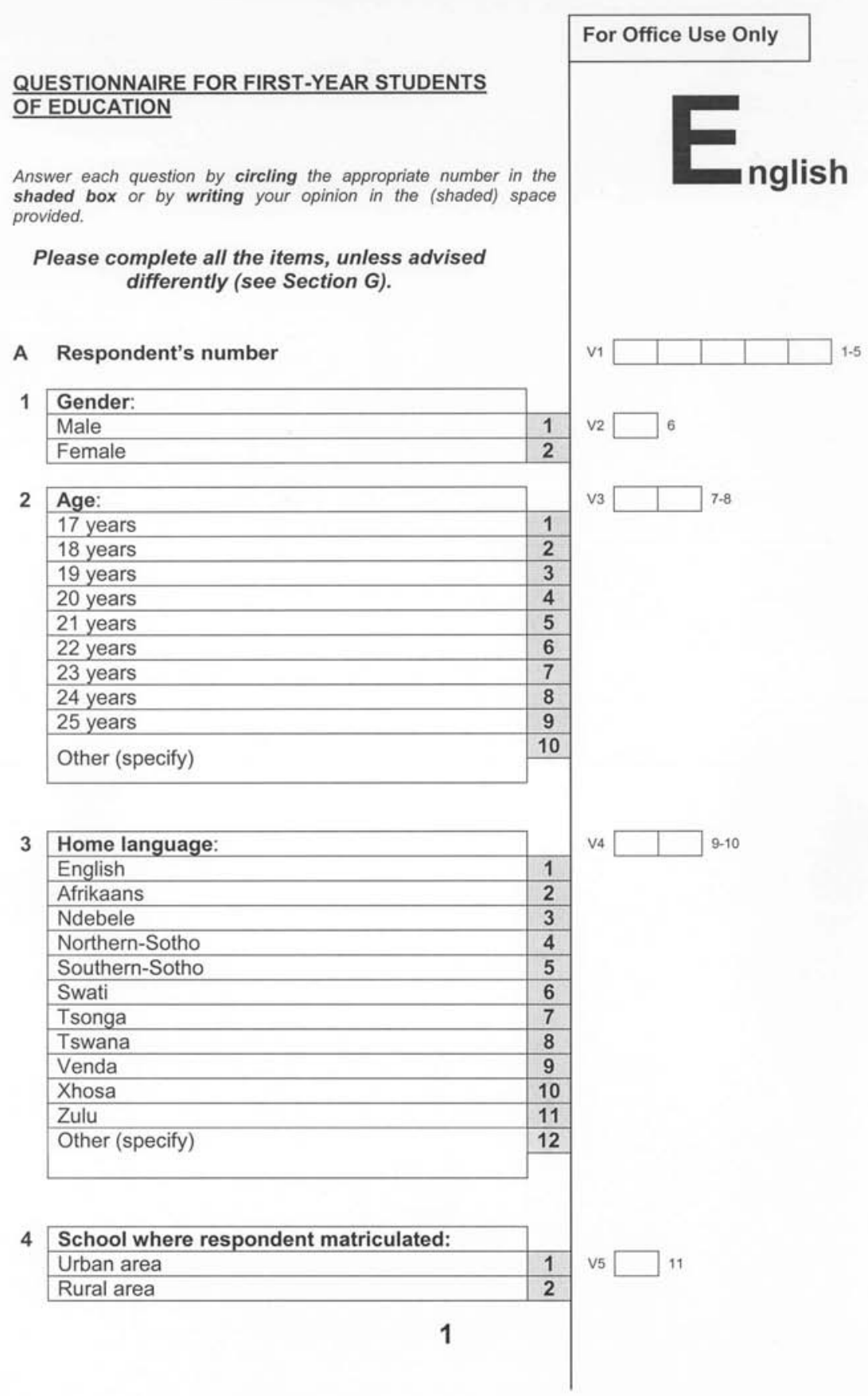


5

\begin{tabular}{|l|l|}
\hline M score achieved: & \\
\hline $25-30$ & $\mathbf{1}$ \\
\hline $19-24$ & 2 \\
\hline $13-18$ & 3 \\
\hline $7-12$ & 4 \\
\hline
\end{tabular}

6 Approximate joint income of parents (per annum):

Above R 300000

R $250000-$ R 299999

R $200000-R 249999$

R $150000-R 199999$

R 100000 - R 149999

R 50000 - R 99999

Less than R 49999

7 What type of accommodation do you have while studying?

Private: Parents

Private: Flat

Private: Commune

Private: Boarding-house (rent a room)

Residence / Hostel

Other (specify)

8 Would you describe your current board and lodging as your first choice of

accommodation?

\begin{tabular}{|l|c|}
\hline Yes & 1 \\
\hline No & 2 \\
\hline If no, specify & \\
\hline
\end{tabular}

9 Programme enrolled for in 2004:

BEd Early Childhood Development and

Foundation Phase (Preschool - Grade 3)

BEd Intermediate Phase (Grades 4-6)

BEd Senior Phase (Grades 7 -9)

BEd General

BEd Human Movement Science and Sport Management

BEd Natural Sciences

BEd Economic and Management Sciences Other (specify)
For Office Use Only

v6

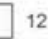

v7

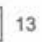

v8
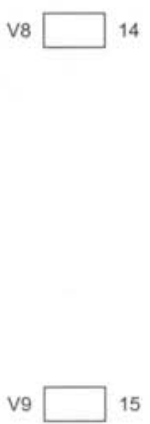

V10 16-17 
B. To what extent has each of the following

For Office Use Only

financial factors influenced your choice of university?

Kindly use one of the following codes:

$1=$ Not at all

2 = Sometimes

$3=$ Often

$4=$ Generally

$5=$ Almost always

10 Availability of study bursaries and loans

11 Cost of field of study \begin{tabular}{l|l|l|l|l|}
1 & 2 & 3 & 4 & 5 \\
\hline
\end{tabular}

v11

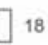

\begin{tabular}{|l|l|l|l|l|l|}
\hline Cost of board and lodging & 1 & 2 & 3 & 4 & 5 \\
\hline
\end{tabular}

13 \begin{tabular}{|l|l|l|l|l|l|}
\hline Availability of accommodation & 1 & 2 & 3 & 4 & 5 \\
\hline
\end{tabular}

C. What expectations do you have of your training for the teaching profession?

Please use one of the following codes:

$1=$ Not at all

2 = Sometimes

$3=$ Often

$4=$ Generally

$5=$ Almost always

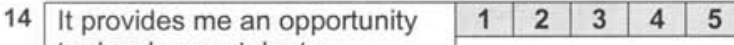
to develop my talents.

\begin{tabular}{|l|l|l|l|l|l|}
\hline 1 I gather that I will be equipped & $\mathbf{1}$ & $\mathbf{2}$ & $\mathbf{3}$ & $\mathbf{4}$ & $\mathbf{5}$ \\
\cline { 2 - 6 }
\end{tabular} to meet the expected /

necessary standards of the profession.

\begin{tabular}{|l|l|l|l|l|l|}
\hline It will help me to achieve & $\mathbf{1}$ & $\mathbf{2}$ & $\mathbf{3}$ & $\mathbf{4}$ & $\mathbf{5}$ \\
\cline { 2 - 6 }
\end{tabular} theoretical knowledge.

17 It will help me to achieve practical competencies.

\begin{tabular}{|l|l|l|l|l|l|}
\hline 1 & 2 & 3 & 4 & 5 \\
\hline & & & & \\
\hline
\end{tabular}

18 It will contribute to my

personal development as a

\begin{tabular}{l|l|l|l|l|}
\hline 1 & 2 & 3 & 4 & 5 \\
\hline
\end{tabular}

leader.

V15

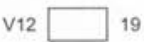

$\mathrm{V} 13 \square 20$

V14

] 21

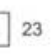

V17 $\square 24$

V18 $\square 25$

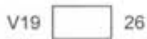


19

It will contribute to my

personal development in the

field of sport.

20 It will contribute to my

personal development on a

cultural level.

21 It will help me to successfully establish interpersonal /

human relationships.

D. To what extent did the following factors contribute to your decision to study in the field of education?

Please use one of the following codes:

$1=$ Not at all

2 = Sometimes

$3=$ Often

$4=$ Generally

$5=$ Almost always

\begin{tabular}{|c|c|c|c|c|c|}
\hline Salary & 1 & 2 & 3 & 4 & 5 \\
\hline Working hours & 1 & 2 & 3 & 4 & 5 \\
\hline Holidays & 1 & 2 & 3 & 4 & 5 \\
\hline \multirow{2}{*}{$\begin{array}{l}\text { Fringe benefits (medical / } \\
\text { housing) }\end{array}$} & 1 & 2 & 3 & 4 & 5 \\
\hline & & & & & \\
\hline Opportunities for promotion & 1 & 2 & 3 & 4 & 5 \\
\hline Job security & 1 & 2 & 3 & 4 & 5 \\
\hline $\begin{array}{l}\text { Opportunity for community } \\
\text { service }\end{array}$ & 1 & 2 & 3 & 4 & 5 \\
\hline
\end{tabular}

29 Opportunity to develop learners' talents

\begin{tabular}{|l|l|l|l|l|l|}
\hline Opportunity for the & 1 & 2 & 3 & 4 & 5 \\
\cline { 2 - 6 }
\end{tabular}

development of own talents
For Office Use Only

V20 $\square 27$

$\mathrm{V} 21 \square 28$

V22 $\square 29$

V23

V24 31

$\mathrm{V} 25 \square 32$

$\mathrm{v}_{26} \square_{33}$

V27 $\square 34$

V28 $\square 35$

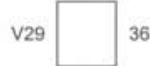

v30 $\square 37$ v31 $\square 38$ 
E. I believe that teaching as a vocation...

For Office Use Only

Please use one of the following codes:

$1=$ Not at all

$2=$ Sometimes

$3=$ Often

$4=$ Generally

$5=$ Almost always

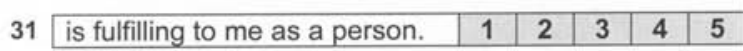

\begin{tabular}{l|l|l|l|l|l|}
\hline is demanding. & $\mathbf{1}$ & $\mathbf{2}$ & $\mathbf{3}$ & $\mathbf{4}$ & $\mathbf{5}$ \\
\hline
\end{tabular}

\begin{tabular}{|l|l|l|l|l|l|}
\hline is challenging. & $\mathbf{1}$ & $\mathbf{2}$ & $\mathbf{3}$ & $\mathbf{4}$ & $\mathbf{5}$ \\
\hline
\end{tabular}

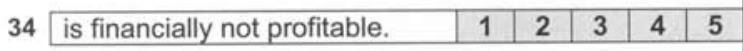

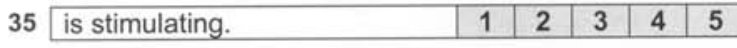

\begin{tabular}{|l|l|l|l|l|l|}
\hline provides an opportunity for me & $\mathbf{1}$ & $\mathbf{2}$ & $\mathbf{3}$ & $\mathbf{4}$ & $\mathbf{5}$ \\
\cline { 2 - 6 } & &
\end{tabular} to develop my creative talents.

\begin{tabular}{|l|l|l|l|l|l|}
\hline 37 is boring. & 1 & 2 & 3 & 4 & 5 \\
\hline
\end{tabular}

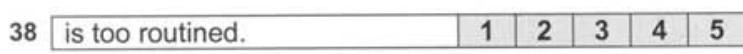

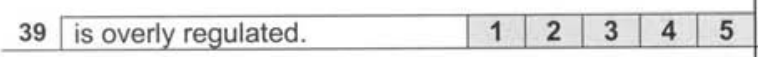

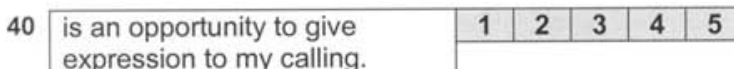

\begin{tabular}{|l|l|l|l|l|l|}
\hline enjoys a high status. & 1 & 2 & 3 & 4 & 5 \\
\hline
\end{tabular}

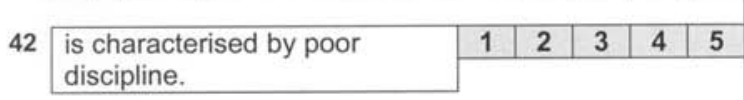

F. Why did you choose this university as your training institution?

Please use one of the following codes:

$\begin{array}{lll}\text { Yes } & =1 \\ \text { No } & =\end{array}$

\begin{tabular}{|l|l|l|}
\hline My parents studied here. & 1 & 2 \\
\hline
\end{tabular}

\begin{tabular}{|l|l|l|}
\hline It is the nearest university to my home. & 1 & 2 \\
\hline
\end{tabular}

V32 $\square 39$

v33 $\square 40$

$\sqrt{34} \square 41$

$v_{35} \square 42$

V36 $\square 43$

v37 $\square 44$

V38 $\square 45$

v39 $\square 46$

V40 47

V41 $\square 48$

V42 $\square 49$

$\mathrm{v}_{43} \square 50$

4 it is the nearest university to my home.

$\mathrm{v}_{44} \square 51$

v45 $\square 52$ 


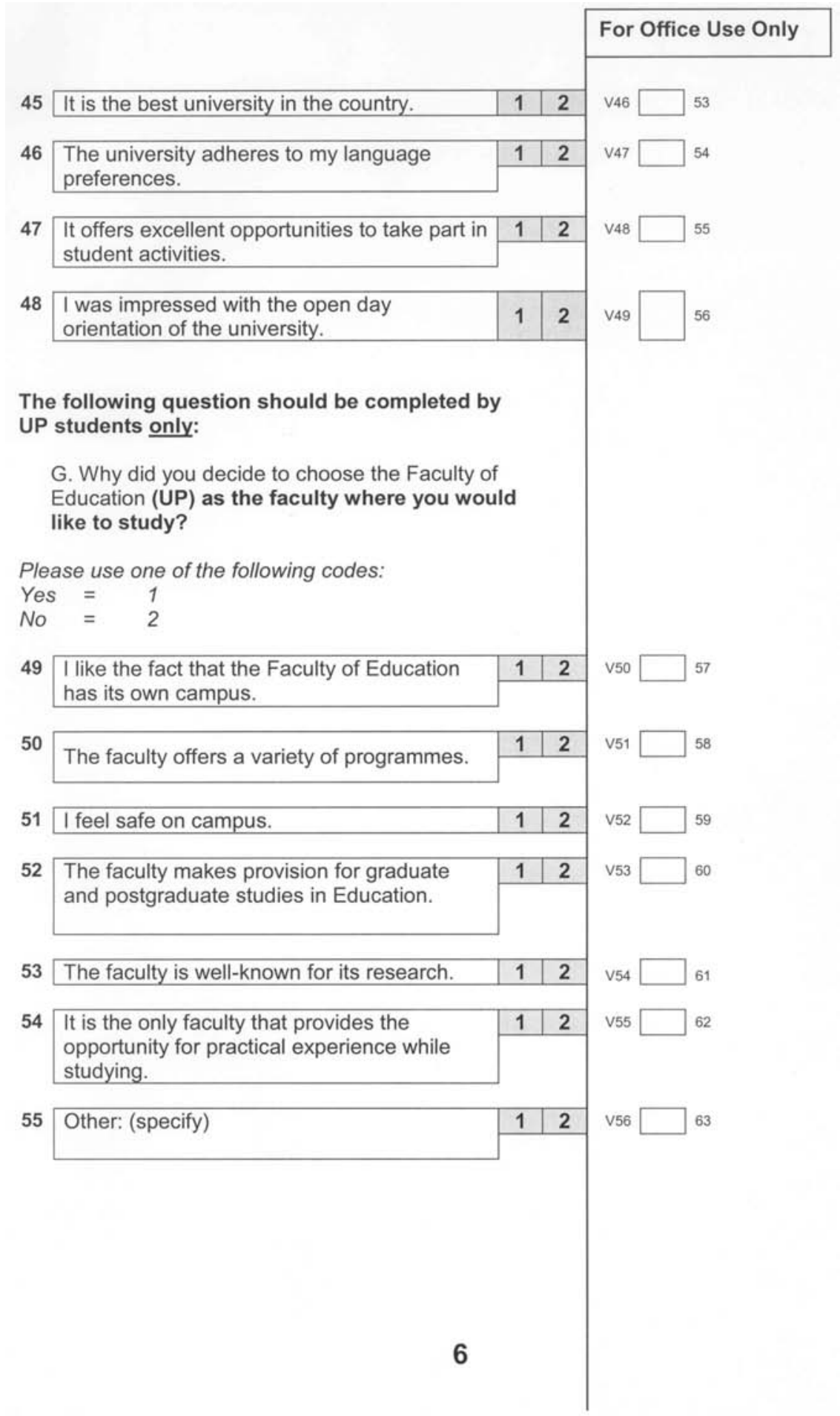




\section{H. The most important reasons for my} choosing teaching as a career:

Please make use of the following codes:

Yes $=1$

No $=2$

56 I want to work with people (especially children).

57 I would like to help learners to gain insight and understanding.

For Office Use Only

58

\begin{tabular}{l|l|l|}
\hline I believe that working with children is an & 1 & 2 \\
\cline { 2 - 3 }
\end{tabular} investment in our country.

\begin{tabular}{l|l|l|l|}
59 & I maintain high moral values, which is why I & 1 & 2 \\
\cline { 2 - 4 }
\end{tabular} want to become an educator.

60 I want a half-day job and school holidays.

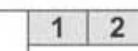

61 My matric results were not good enough to allow me to study for something else.

62 I wasn't accepted by the faculty of my first choice.

63 I have a passion for education and would like to make a difference.

64 I have always wanted to become an educator. 
I. To what extent did each of the following of a university?

Please make use of the following codes:

Large extent

Small extent

$=1$

65 Language policy of the university: Mother tongue instruction / Parallel medium

66 Teaching policy

67 Assessment policy: examination system / promotion

\begin{tabular}{|l|l|l|}
\hline Sports facilities & 1 & 2 \\
\hline
\end{tabular}

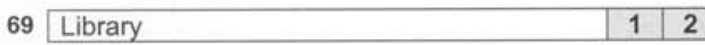

\begin{tabular}{|l|l|l|}
\hline 70 Computer facilities & $\mathbf{1}$ & 2 \\
\hline
\end{tabular}

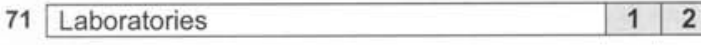

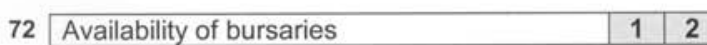

\begin{tabular}{|l|l|l|}
\hline Approachability of lecturers & 1 & 2 \\
\hline
\end{tabular}

I. Which of the following persons had the greatest influence on your choice of teaching as a career?

Rank these persons or group from 1 to $8 / 9$, where 1 represents the person or group who influenced you most and $8 / 9$ the person or group who influenced you least.

1 Parents

2 Other family members

3 School principal

4 Career guidance educator

5 Other educator(s)

6 Peer group

\section{For Office Use Only}

factors influence your choice

V69 $\square 76$

v70 $\square 77$

V71 $\square 78$

v72 $\square 79$

v73 $\square 80$

v74 $\square 81$

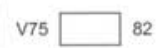

V76 $\square 83$

v77 84

v78 $\square 85$

v79 $\square 86$

v80 $\square 87$ 


\begin{tabular}{|c|c|c|c|}
\hline \multirow[b]{2}{*}{$\mathrm{I}$} & \multirow[b]{2}{*}{ Role models (e.g. sports coach) } & \multicolumn{2}{|c|}{ For Office Use Only } \\
\hline & & v81 & 88 \\
\hline 8 & Religious leader & v82 & 89 \\
\hline 9 & Other (specify) & V83 & 90 \\
\hline & & $\begin{array}{r}\text { V83 } \\
B\end{array}$ & 90 \\
\hline
\end{tabular}

Please complete:

I believe that teaching as a vocation offers me ...

a positive future because ...

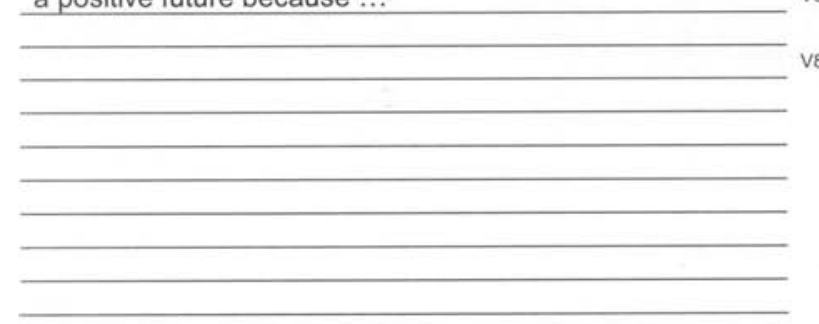

v84

v85 91-92 93-94

a not so positive future because ... v86

v87

\begin{tabular}{|c|c|c|}
\hline 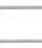 & & $95-96$ \\
\hline
\end{tabular}

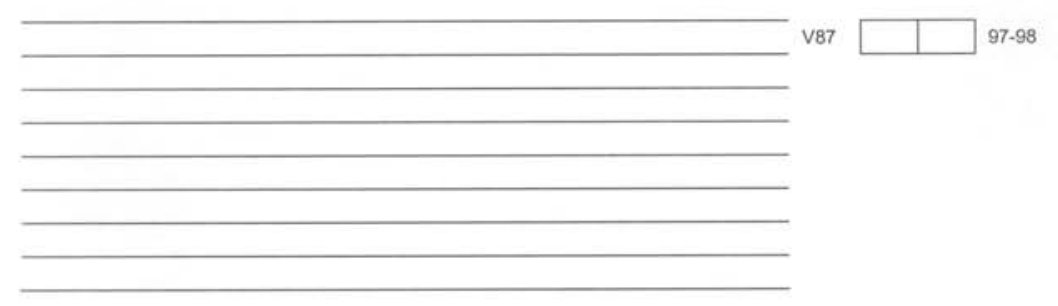

